\title{
Vocal Motor Performance in Birdsong Requires Brain-Body Interaction
}

\author{
(1) Iris Adam and ${ }^{\circledR}$ Coen P. H. Elemans
}

https://doi.org/10.1523/ENEURO.0053-19.2019

Department of Biology, University of Southern Denmark, 5230 Odense, Denmark

Key words: development; motor control; muscle training; sensorimotor learning; songbird

\section{Significance Statement}

Motor skill learning typically occurs in a period when the brain needs to navigate a body that is still growing and developing. How the changing body, neural circuit formation, and motor coding influence each other remains unknown. Songbirds provide excellent model systems to study motor skill learning. It has recently been shown that songbird vocal muscles double in speed during sensorimotor learning. Here we argue that these contractile as well as morphological changes stem predominantly from use and only secondarily from hormones or genetic programs. This implies that muscle training constrains skill-learning trajectories. As contractile muscle property changes must require altered motor codes for achieving the same acoustic targets, the final performance results from interactions between brain and body.

\section{Introduction}

Understanding how novel behaviors are learned remains a major challenge to modern neuroscience. Acquiring and mastering fine motor skills, from dexterity in piano playing to microsurgery or speech, can take weeks to months or even years and is strongly affected by injury, stroke, and developmental as well as neurodegenerative disorders. Most fine motor skill learning occurs postnatally from infancy to adolescence when the brain needs to navigate a body that is exhibiting large changes due to growth and development. Changes in neural coding and circuit development remain challenging to follow over

Received February 8, 2019; accepted May 24, 2019; First published June 10, 2019.

The authors declare no competing financial interests.

Author contributions: I.A. and C.P.H.E. wrote the paper.

This work was supported by Det Frie Forskningsråd (DFF-5051-00195) and the Carlsberg Foundation (CF17-0949) to I.A., and the NovoNordisk Foundation (NNF17OC0028928) to C.P.H.E. We thank the anonymous reviewers for their constructive comments, which helped to improve and clarify the final version of the paper.

Correspondence should be addressed to Iris Adam at irisadam@ biology.sdu.dk or Coen P. H. Elemans at coen@biology.sdu.dk.

https://doi.org/10.1523/ENEURO.0053-19.2019

Copyright (C) 2019 Adam and Elemans

This is an open-access article distributed under the terms of the Creative Commons Attribution 4.0 International license, which permits unrestricted use, distribution and reproduction in any medium provided that the original work is properly attributed. meaningful timescales in single individuals and are thus typically studied during rather brief periods in adult subjects (Li et al., 2001; Xiao et al., 2006) or during recovery after injury (Nudo et al., 1996; Dancause et al., 2005). Songbirds however, provide a powerful and unique system to study motor skill learning over ethologically meaningful time scales (Brainard and Doupe, 2013).

The brain does not function in isolation. All animal behaviors result from complex system-wide interactions between nervous system, body, and surrounding environment (Chiel and Beer, 1997; Lum et al., 2005; Nishikawa et al., 2007; Tytell et al., 2011; Düring and Elemans, 2016; Sober et al., 2018). Motor pathways produce precisely timed complex sequences of motor commands to activate muscles. The forces ultimately generated by muscles strongly depend on dynamic body motion and environmental conditions through the muscle's nonlinear force-length and force-velocity properties (Düring and Elemans, 2016). Thus, motor control systems are closed-loop systems (Roth et al., 2014) and the activity of neural circuits can be understood only by considering the biomechanics of muscles, bodies, and the exterior world (Tytell et al., 2011).

How the developing body influences circuit formation and neural coding in the brain and vice versa is still largely unknown (Avitan and Goodhill, 2018). Recent work showed that developmental changes in vocal behavior of marmoset monkeys that were typically attributed to neural 
changes can be explained by changes in the body (i.e., growth of the lungs; Zhang and Ghazanfar, 2018), emphasizing the need for an embodied view on motor control during vocal development.

In this opinion piece, we argue that contractile changes occurring in the vocal muscles of songbirds during song learning stem predominantly from interactions between brain and body. This implies that extensive training of syringeal muscles is essential to achieve their maximal performance and that the duration and trajectory of song learning are not solely set by neural circuit formation. Given that virtually all motor skills or at least their building blocks are acquired during times while the body is still changing, truly understanding motor coding and its pathologies requires rethinking and an embodied approach to understand motor learning.

\section{Songbird brain and body change over vocal development}

The sensorimotor phase of song learning in zebra finches takes $\sim 2$ months and starts when juveniles start producing subsong at $28 \mathrm{~d}$ post-hatching (DPH). Song development proceeds from subsong through plastic song to adult, so-called crystallized song, which is reached $\sim 100 \mathrm{DPH}$ (Roper and Zann, 2006). Over the course of vocal development, a network of discrete interconnected forebrain nuclei dedicated to learn and produce song (hereafter referred to as song system) is changing profoundly in morphology and function. Significant research effort has been dedicated to describing and understanding learning related changes in the brain during vocal development in songbirds (Fee and Goldberg, 2011; Brainard and Doupe, 2013). However, despite our rapidly advancing knowledge of the song system, unfortunately very little is known about the motor code that drives the three main motor systems involved in sound production: the vocal organ, the syrinx; the respiratory system; and upper vocal tract (Elemans, 2014; Schmidt and Goller, 2016). The motor neurons that control all these muscles are all located in small oblong nuclei in the brainstem (Schmidt and Martin Wild, 2014) and their location and small size complicates chronic recording in freely behaving animals even in adults (Williams and Nottebohm, 1985). At the terminus of the premotor pathway of the song system, in vivo recordings show that over vocal development the premotor neurons gradually change their firing pattern from highly variable patterns into sparse high-frequency bursts (Ölveczky et al., 2011). In adult males these premotor neurons are precisely locked to song timing (Sober et al., 2008; Ölveczky et al., 2011) and can causally explain variation in biomechanics and behavior of the respiratory motor system (Srivastava et al., 2017).

In parallel, the syrinx also exhibits changes during the sensorimotor learning phase. Syringeal muscle mass and cross-sectional area increase from hatching to adulthood and sex differences can be found after $20 \mathrm{DPH}$ in zebra finches (Godsave et al., 2002). However, such morphological changes do not allow reliable inferences about changes in contractile properties of the muscle, such as contraction speed, maximal tension, force-length, and force-velocity profiles. Because contractile muscle properties determine the forces that act on body and environment, they are critical traits for understanding the biomechanics of vocal production and thereby linking motor commands to behavioral output, i.e., song. It has recently been shown that over song learning, the superfast syringeal muscles controlling song double in isometric contraction speed and ultimately reach the maximal attainable speed possible in vertebrate synchronous muscle (Mead et al., 2017). The muscle speed increase was associated with a composition change of expressed heavy myosin chain gene isoforms $(M Y H)$ toward nearexclusive expression of $\mathrm{MYH13}$ aka superfast myosin (Mead et al., 2017). Concluding, over vocal development syringeal muscles exhibit changes in morphology as well as contractile properties.

In the following sections we will review the three most likely factors that could drive these changes: hormones, an innate developmental program, or neural drive.

\section{Hormonally mediated changes cannot explain adult syrinx dimorphism}

In adult zebra finches, the entire song system, including the syrinx, exhibits differences between sexes. Most nuclei of the song system are smaller in females (NixdorfBergweiler, 1996; Shaughnessy et al., 2019), females have a smaller motor nucleus projecting to the syrinx (Godsave et al., 2002; Wade et al., 2002), the syrinx itself is also smaller with a less developed skeleton (Düring et al., 2013), and syringeal muscles have less mass (Bleisch et al., 1984; Wade and Buhlman, 2000; Düring et al., 2013) and a lower contraction speed (Elemans et al., 2008), albeit still nearly two orders of magnitude faster than locomotory muscles. Moreover, syrinx muscles in females express less MYH13 than in males (Mead et al., 2017). The sexual dimorphic nature of these observations suggests that these traits are mediated by gonadal steroid hormones.

In general, this hypothesis is supported by previous studies showing that the syrinx is sensitive to manipulations of steroid hormone levels: treating adult females with testosterone increases muscle mass, fiber diameter, and number of acetylcholine receptors, masculinizing the syrinx (Bleisch et al., 1984; Wade and Buhlman, 2000). Similarly, decreasing testosterone levels in males feminizes the syrinx, which is reflected in a loss of muscle mass (Luine et al., 1980; Bleisch et al., 1984; Wade and Buhlman, 2000). However, masculinization never reaches male levels and axotomizing (severing the innervating nerve) the syrinx of testosterone-treated females abolishes masculinization (Bleisch et al., 1984; Wade and Buhlman, 2000), which indicates that sex differences in syringeal properties are not solely driven by steroid hormones. This is further supported by the finding that androgen receptor expression only gets dimorphic after 30 DPH, $10 \mathrm{~d}$ after muscle weight and cross-sectional-area start to be different between the sexes (Godsave et al., 2002). Thus, the changes in muscle morphology seem to 
be driven by the change in neural drive because of the onset of singing activity in males $\sim 28 \mathrm{DPH}$ (Arnold, 1975) rather than direct action of hormones on the syrinx. This hypothesis is further strengthened by the finding that castration changes the normal song learning trajectory only slightly, mostly by decreasing the amount of song per day and delaying crystallization in some but not all animals (Arnold, 1975).

Together we conclude that steroid hormones are critical but not sufficient to induce and maintain sexual dimorphism of the syrinx.

\section{Muscle use drives morphological and contractile changes}

Skeletal muscle functionality is known to change with use in adults or after peripheral nerve damage and use reduction causes muscle atrophy (Buller et al., 1960, 1987; Lømo, 2003; Schiaffino and Reggiani, 2011). As such, the most drastic experiment to investigate neural drive on muscles is axotomy, i.e., to severe the nerve innervating the muscle. Axotomizing the syrinx in songbirds leads to a decrease in fundamental frequency and amplitude of the produced sound and the conversion of all syllables into harmonic stacks because of the loss of fast frequency modulations (Williams et al., 1992; Daley and Goller, 2004; Roy and Mooney, 2007; Secora et al., 2012; Vallentin and Long, 2015). Morphologically, syringeal muscles atrophy after axotomy (Urbano et al., 2013), suggesting that usage is required to maintain muscle mass. However, it remains unknown how axotomy affects contraction related properties, such as contraction speed, force-length and force-velocity profiles, MYH composition, and $\mathrm{MYH13}$ expression in particular.

The discovery of MYH13 expression in syringeal muscles (Mead et al., 2017) placed them conclusively in the lineage of craniofacial muscles, corroborating earlier developmental studies (Noden et al., 1999; Noden and Francis-West, 2006). These skeletal muscles can uniquely express several rare myosin heavy chain isoforms, among them MYH13. The craniofacial muscles also include extraocular and most laryngeal muscles (Briggs and Schachat, 2000; Hoh, 2010) and are characterized by extremely fast force development, reaching maximal tension within a few milliseconds (Elemans et al., 2008; McLoon and Andrade, 2012). MYH13 has been proposed to be responsible for very high contraction speeds and this notion is strengthened by the unusually high detachment rate from actin (Bloemink et al., 2013).

In our opinion, the most likely hypothesis to explain the upregulation of $M Y H 13$ and doubling in contraction speed in the syrinx during song learning is that the increased use, or training, of muscles is causally driving these changes. This hypothesis is supported by three lines of evidence:

Timescale of upregulation. In all craniofacial muscles studied to date that express myosin MYH13, contraction speed as well as MYH13 expression increase over a similar, relatively slow (i.e., weeks) time course after birth. In songbirds, MYH13 expression changes over 2 months during sensorimotor learning (Mead et al., 2017). In kit- tens, twitch speed as well as tetanic tension of extraocular muscles increases during the first 20 weeks of life (Lennerstrand and Hanson, 1978). In mouse and rat extraocular muscles and the rat larynx MYH13 expression increases over the first 20-30 d of life (Shiotani et al., 1999; Zhou et al., 2010; Moncman et al., 2011), but to our knowledge no data on the development of contraction speed is available in these muscles.

Neural drive influences muscle speed and MYH expression. In general, skeletal muscle functionality changes with neural drive. Use reduction causes muscle atrophy (Buller et al., 1960, 1987; Lømo, 2003; Schiaffino and Reggiani, 2011) and transnervation with a faster spiking nerve increases contraction speed (Paniello et al., 2001). Neural stimulation is known to drive $M Y H$ expression patterns and contraction speed: in rats, neural activity associated with optokinetic and vestibulo-ocular reflexes stimulates $\mathrm{MYH13}$ expression in extraocular muscles (Brueckner et al., 1999; Moncman et al., 2011). In kittens, the earlier described postnatal increase in contraction speed is impeded by impairing binocular vision (Lennerstrand, 1979; Lennerstrand and Hanson, 1979). Likewise, upregulation of MYH13 in rodent extraocular and laryngeal muscles is prevented by visual deprivation or axotomizing the larynx, respectively (Brueckner and Porter, 1998; Shiotani and Flint, 1998; Brueckner et al., 1999), which in addition provides evidence against the hypothesis that a fixed postnatal developmental program controls MYH13 upregulation. Last, in all MYH13 expressing craniofacial muscles, the increase in contraction speed and $\mathrm{MYH13}$ expression coincides with the onset of muscle use (Lennerstrand and Hanson, 1978; Shiotani et al., 1999; Zhou et al., 2010; Moncman et al., 2011; Mead et al., 2017).

Location of MYH13 transcription. In particular the expression of MYH13 opens the possibility that changes in the properties of syringeal muscles are driven by neural activity, as MYH13 is known to be transcribed close to the neuromuscular junction in extraocular muscles (Briggs and Schachat, 2002). It has been speculated that the electrical or chemical activation of motor neurons directly stimulates MYH13 transcription linked to acetylcholine receptors (Sanes and Lichtman, 2001; Rubinstein et al., 2004). However, it is unknown to what extent the amount of stimulation affects $M Y H 13$ transcription and other muscle properties.

\section{Conclusions and implications}

Together the data above strongly suggest that the postnatal increase in muscle speed and MYH13 expression in the songbird syrinx is primarily caused by the use of the muscles and only secondarily because of hormones and innate genetic programs.

We propose this hypothesis has several implications for motor learning:

Time course of song learning is set by muscle training. Because previous work established that MYH13 expression is regulated by use and correlates to speed, we suggest that extensive use of syringeal muscles is essential to achieve their maximal speed. The timescale of 
MYH13 upregulation in craniofacial muscles is $>4$ weeks in all studied model systems, and $\sim 7$ weeks in songbirds. Because this duration overlaps the typical temporal trajectory for skeletal muscle endurance or speed training, we speculate that the total duration and trajectory of song learning is not solely set by neural circuit formation but must also be required for muscle training. As female songbirds may be able to perceive millisecond scale variations (Prior et al., 2018) and prefer sped-up song in several species (Drăgănoiu et al., 2002; Weiss et al., 2012), we further speculate that millisecond fine-scale acoustic modulations, such as frequency modulation or on- and offset precision, can act as an honest signal (Searcy and Nowicki, 2005) for metabolic energy invested in muscle training.

Execution error is constrained by immature motor code and muscle speed. In adults, premotor codes and song behavior occur at millisecond scale precision (Chi and Margoliash, 2001; Hahnloser et al., 2002) and recently variation in spike timing at millisecond timescales has been shown to causally affect biomechanics and behavior (Tang et al., 2014; Srivastava et al., 2017; Sober et al., 2018). In contrast, the plastic phase of song learning is marked by a higher rendition to rendition variability in acoustic parameters like syllable duration and frequency (Ali et al., 2013). This variability is essential for vocal exploration during trial and error learning (Charlesworth et al., 2011) and thought to be driven mostly by the basal ganglia (Kojima et al., 2018). We propose an additional interpretation: faster muscles allow a more temporally precise actuation to achieve acoustic targets leading to less variability in, e.g., duration of syllables. In other words, we assume that muscle speed increase leads to execution error decrease. We hypothesize that the (initially) slower superfast syringeal muscles constrain the precision to execute motor sequences during vocal learning, especially at the start of song ontogeny. We predict that variable vocalizations observed during song learning reflect immature brain circuits as well as muscle speed.

Changes in contraction speed require motor code adaptation for achieving the same target. During motor learning, animals try to minimize error for achieving task-specific motor targets. In the zebra finch, the acoustic song template is considered to not change during sensorimotor learning (Mooney, 2009). As contraction speed of syringeal muscles changes over the course of weeks, playing a hypothetical stereotyped motor code will lead to changes in force profiles. Consequently, the acoustic targets, such as amplitude, entropy, or fundamental frequency, will also change and in turn lead to changes in error magnitude. Thus, we propose that the observed contractile changes of syringeal muscles require altering the motor code during development to achieve the same force profiles and acoustic targets.

The hypotheses presented above remain to be tested experimentally. Only with a systems view will we be able to explain and understand the development of complex behaviors. Given the dedicated neural, muscular, and genetic substrates, the knowledge accrued to date and the increasing number of genetic tools (from RNAinterference to DREADDs and optogenetics) available to the field, birdsong is an ideal system to embrace such an integrative approach.

\section{References}

Ali F, Otchy TM, Pehlevan C, Fantana AL, Burak Y, Ölveczky BP (2013) The basal ganglia is necessary for learning spectral, but not temporal, features of birdsong. Neuron 80:494-506.

Arnold AP (1975) The effects of castration on song development in zebra finches (Poephila guttata). J Exp Zool 191:261-278.

Avitan L, Goodhill GJ (2018) Code under construction: neural coding over development. Trends Neurosci 41:599-609.

Bleisch W, Luine VN, Nottebohm F (1984) Modification of synapses in androgen-sensitive muscle. I. Hormonal regulation of acetylcholine receptor number in the songbird syrinx. J Neurosci 4:786-792.

Bloemink MJ, Deacon JC, Resnicow DI, Leinwand LA, Geeves MA (2013) The superfast human extraocular myosin is kinetically distinct from the fast skeletal Ila, Ilb, and Ild isoforms. J Biol Chem 288:27469-27479.

Brainard MS, Doupe AJ (2013) Translating birdsong: songbirds as a model for basic and applied medical research. Ann Rev Neurosci 36:489-517.

Briggs MM, Schachat F (2000) Early specialization of the superfast myosin in extraocular and laryngeal muscles. J Exp Biol 203:24852494.

Briggs MM, Schachat F (2002) The superfast extraocular myosin (MYH13) is localized to the innervation zone in both the global and orbital layers of rabbit extraocular muscle. J Exp Biol 205:31333142.

Brueckner JK, Porter JD (1998) Visual system maldevelopment disrupts extraocular muscle-specific myosin expression. J Appl Physiol 85:584-592.

Brueckner JK, Ashby LP, Prichard JR, Porter JD (1999) Vestibuloocular pathways modulate extraocular muscle myosin expression patterns. Cell Tissue Res 295:477-484

Buller AJ, Eccles JC, Eccles RM (1960) Interactions between motoneurones and muscles in respect of the characteristic speeds of their responses. J Physiol 150:417-439.

Buller AJ, Kean CJ, Ranatunga KW (1987) Transformation of contraction speed in muscle following cross-reinnervation; dependence on muscle size. J Muscle Res Cell Motil 8:504-516.

Charlesworth JD, Tumer EC, Warren TL, Brainard MS (2011) Learning the microstructure of successful behavior. Nat Neurosci 14: 373-380.

Chi Z, Margoliash D (2001) Temporal precision and temporal drift in brain and behavior of zebra finch song. Neuron 32:899-910.

Chiel HJ, Beer RD (1997) The brain has a body: adaptive behavior emerges from interactions of nervous system, body and environment. Trends Neurosci 20:553-557.

Daley M, Goller F (2004) Tracheal length changes during zebra finch song and their possible role in upper vocal tract filtering. J Neurobiol 59:319-330.

Dancause N, Barbay S, Frost SB, Plautz EJ, Chen D, Zoubina EV, Stowe AM, Nudo RJ (2005) Extensive cortical rewiring after brain injury. J Neurosci 25:10167-10179.

Drăgănoiu TI, Nagle L, Kreutzer M (2002) Directional female preference for an exaggerated male trait in canary (Serinus canaria) song. Proc Biol Sci 269:2525-2531.

Düring DN, Ziegler A, Thompson CK, Ziegler A, Faber C, Müller J, Scharff C, Elemans CP (2013) The songbird syrinx morphome: a three-dimensional, high-resolution, interactive morphological map of the zebra finch vocal organ. BMC Biol 11:1. 
Düring DN, Elemans CPH (2016) Embodied motor control of avian vocal production. In: Vertebrate sound production and acoustic communication (Suthers RA, Fitch WT, Fay RR, Popper AN, eds), pp 119-157. Cham: Springer.

Elemans CP (2014) The singer and the song: the neuromechanics of avian sound production. Curr Opin Neurobiol 28:172-178.

Elemans CP, Mead AF, Rome LC, Goller F (2008) Superfast vocal muscles control song production in songbirds. PLoS One 3:e2581.

Fee MS, Goldberg JH (2011) A hypothesis for basal gangliadependent reinforcement learning in the songbird. Neuroscience 198:152-170.

Godsave SF, Lohmann R, Vloet RP, Gahr M (2002) Androgen receptors in the embryonic zebra finch hindbrain suggest a function for maternal androgens in perihatching survival. J Comp Neurol 453: $57-70$.

Hahnloser RH, Kozhevnikov AA, Fee MS (2002) An ultra-sparse code underlies the generation of neural sequences in a songbird. Nature 419:65-70.

Hoh JFY (2010) Laryngeal muscles as highly specialized organs in airway protection, respiration and phonation. Hbk Behav Neurosci 19:13-21.

Kojima S, Kao MH, Doupe AJ, Brainard MS (2018) The avian basal ganglia are a source of rapid behavioral variation that enables vocal motor exploration. J Neurosci 38:9635-9647.

Lennerstrand G (1979) Contractile properties of extraocular muscle in Siamese cat. Acta Ophthalmol (Copenh) 57:1030-1038.

Lennerstrand G, Hanson J (1978) The postnatal development of the inferior oblique muscle of the cat: I. Isometric twitch and tetanic properties. Acta Physiol Scand 103:132-143.

Lennerstrand G, Hanson J (1979) Contractile properties of extraocular muscle in cats reared with monocular lid closure and artificial squint. Acta Ophthalmol 57:591-599.

Li CS, Padoa-Schioppa C, Bizzi E (2001) Neuronal correlates of motor performance and motor learning in the primary motor cortex of monkeys adapting to an external force field. Neuron 30:593-607.

Lømo T (2003) Nerve-muscle interactions. In: Handbook of clinical neurophysiology, pp 47-65. Amsterdam, Boston: Elsevier.

Luine V, Nottebohm F, Harding C, McEwen BS (1980) Androgen affects cholinergic enzymes in syringeal motor neurons and muscle. Brain Res 192:89-107.

Lum CS, Zhurov Y, Cropper EC, Weiss KR, Brezina V (2005) Variability of swallowing performance in intact, freely feeding Aplysia. J Neurophysiol 94:2427-2446.

McLoon LK, Andrade F (2012) Craniofacial muscles: a new framework for understanding the effector side of craniofacial muscle control. New York: Springer.

Mead AF, Osinalde N, Ortenblad N, Nielsen J, Brewer J, Vellema M, Adam I, Scharff C, Song Y, Frandsen U, Blagoev B, Kratchmarova I, Elemans CP (2017) Fundamental constraints in synchronous muscle limit superfast motor control in vertebrates. eLife 6:e29425.

Moncman CL, Andrade ME, Andrade FH (2011) Postnatal changes in the developing rat extraocular muscles. Invest Ophthalmol Vis Sci 52:3962-3969.

Mooney R (2009) Neural mechanisms for learned birdsong. Learn Mem 16:655-669.

Nishikawa K, Biewener AA, Aerts P, Ahn AN, Chiel HJ, Daley MA, Daniel TL, Full RJ, Hale ME, Hedrick TL, Lappin AK, Nichols TR, Quinn RD, Satterlie RA, Szymik B (2007) Neuromechanics: an integrative approach for understanding motor control. Integr Comp Biol 47:16-54.

Nixdorf-Bergweiler BE (1996) Divergent and parallel development in volume sizes of telencephalic song nuclei in male and female zebra finches. J Comp Neurol 375:445-456.

Noden DM, Francis-West P (2006) The differentiation and morphogenesis of craniofacial muscles. Dev Dyn 235:1194-1218.

Noden DM, Marcucio R, Borycki AG, Emerson CP Jr (1999) Differentiation of avian craniofacial muscles: I. Patterns of early regulatory gene expression and myosin heavy chain synthesis. Dev Dyn 216:96-112.
Nudo RJ, Wise BM, SiFuentes F, Milliken GW (1996) Neural substrates for the effects of rehabilitative training on motor recovery after ischemic infarct. Science 272:1791-1794.

Ölveczky BP, Otchy TM, Goldberg JH, Aronov D, Fee MS (2011) Changes in the neural control of a complex motor sequence during learning. J Neurophysiol 106:386-397.

Paniello RC, West SE, Lee P (2001) Laryngeal reinnervation with the hypoglossal nerve: I. Physiology, histochemistry, electromyography, and retrograde labeling in a canine model. Ann Otol Rhinol Laryngol 110:532-542.

Prior NH, Smith E, Lawson S, Ball GF, Dooling RJ (2018) Acoustic fine structure may encode biologically relevant information for zebra finches. Sci Rep 8:6212.

Roper A, Zann R (2006) The onset of song learning and song tutor selection in fledgling zebra finches. Ethology 112:458-470.

Roth E, Sponberg S, Cowan NJ (2014) A comparative approach to closed-loop computation. Curr Opin Neurobiol 25:54-62.

Roy A, Mooney R (2007) Auditory plasticity in a basal gangliaforebrain pathway during decrystallization of adult birdsong. $J$ Neurosci 27:6374-6387.

Rubinstein NA, Porter JD, Hoh JF (2004) The development of longitudinal variation of Myosin isoforms in the orbital fibers of extraocular muscles of rats. Invest Ophthalmol Vis Sci 45:3067-3072.

Sanes JR, Lichtman JW (2001) Induction, assembly, maturation and maintenance of a postsynaptic apparatus. Nat Rev Neurosci 2:791-805.

Schiaffino S, Reggiani C (2011) Fiber types in mammalian skeletal muscles. Physiol Rev 91:1447-1531.

Schmidt MF, Martin Wild J (2014) The respiratory-vocal system of songbirds: anatomy, physiology, and neural control. Prog Brain Res 212:297-335.

Schmidt MF, Goller F (2016) Breathtaking songs: coordinating the neural circuits for breathing and singing. Physiology 31:442-451.

Searcy WA, Nowicki S (2005) The evolution of animal communication: reliability and deception in signaling systems. Princeton UP: Princeton University Press.

Secora KR, Peterson JR, Urbano CM, Chung B, Okanoya K, Cooper BG (2012) Syringeal specialization of frequency control during song production in the Bengalese finch (Lonchura striata domestica). PLoS One 7:e34135.

Shaughnessy DW, Hyson RL, Bertram R, Wu W, Johnson F (2019) Female zebra finches do not sing yet share neural pathways necessary for singing in males. J Comp Neurol 527:843-855.

Shiotani A, Flint PW (1998) Myosin heavy chain composition in rat laryngeal muscles after denervation. Laryngoscope 108:1225-1229.

Shiotani A, Jones RM, Flint PW (1999) Postnatal development of myosin heavy chain isoforms in rat laryngeal muscles. Ann Otol Rhinol Laryngol 108:509-515.

Sober SJ, Wohlgemuth MJ, Brainard MS (2008) Central contributions to acoustic variation in birdsong. J Neurosci 28:10370-10379.

Sober SJ, Sponberg S, Nemenman I, Ting LH (2018) Millisecond spike timing codes for motor control. Trends Neurosci 41:644648.

Srivastava $\mathrm{KH}$, Holmes $\mathrm{CM}$, Vellema M, Pack AR, Elemans $\mathrm{CPH}$, Nemenman I, Sober SJ (2017) Motor control by precisely timed spike patterns. Proc Natl Acad Sci U S A 114:1171-1176.

Tang C, Chehayeb D, Srivastava K, Nemenman I, Sober SJ (2014) Millisecond-scale motor encoding in a cortical vocal area. PLoS Biol 12:e1002018.

Tytell ED, Holmes P, Cohen AH (2011) Spikes alone do not behavior make: why neuroscience needs biomechanics. Curr Opin Neurobiol 21:816-822.

Urbano CM, Peterson JR, Cooper BG (2013) Exploring vocal recovery after cranial nerve injury in Bengalese finches. Neurosci Lett 534:112-116.

Vallentin D, Long MA (2015) Motor origin of precise synaptic inputs onto forebrain neurons driving a skilled behavior. J Neurosci 35: 299-307. 
Wade J, Buhlman L (2000) Lateralization and effects of adult androgen in a sexually dimorphic neuromuscular system controlling song in zebra finches. J Comp Neurol 426:154-164.

Wade J, Buhlman L, Swender D (2002) Post-hatching hormonal modulation of a sexually dimorphic neuromuscular system controlling song in zebra finches. Brain Res 929:191-201.

Weiss M, Kiefer S, Kipper S (2012) Buzzwords in females' ears? The use of buzz songs in the communication of nightingales (Luscinia megarhynchos). PLoS One 7:e45057.

Williams H, Nottebohm F (1985) Auditory responses in avian vocal motor neurons: a motor theory for song perception in birds. Science 229:279282.
Williams H, Crane LA, Hale TK, Esposito MA, Nottebohm F (1992) Right-side dominance for song control in the zebra finch. J Neurobiol 23:1006-1020.

Xiao J, Padoa-Schioppa C, Bizzi E (2006) Neuronal correlates of movement dynamics in the dorsal and ventral premotor area in the monkey. Exp Brain Res 168:106-119.

Zhang YS, Ghazanfar AA (2018) Vocal development through morphological computation. PLoS Biol 16:e2003933.

Zhou Y, Liu D, Kaminski HJ (2010) Myosin heavy chain expression in mouse extraocular muscle: more complex than expected. Invest Ophthalmol Vis Sci 51:6355-6363. 